\title{
CENTRAL BANK CREDIBILITY: DETERMINANTS AND MEASUREMENT. A CROSS-COUNTRY STUDY*
}

\author{
Joanna MACKIEWICZ-ŁYZIAK \\ (Received: 21 February 2014; revision received: 25 September 2014; \\ accepted: 21 April 2015)
}

This paper proposes a new measure of central bank credibility - the credibility index calculated on the basis of the key determinants of central bank credibility. The index is compiled for 9 countries: the Czech Republic, Hungary, Slovakia, Poland, Chile, Brazil, Turkey, United Kingdom and Sweden, for the years 1999-2007. The results are cross-checked with other credibility measures based on inflation expectations of two groups of economic agents. The analysis demonstrates that the credibility index may be considered a relevant and consistent credibility measure.

Keywords: central bank, monetary policy, credibility, transparency

JEL classification indices: C22, D12, D84, E52 * I thank the two anonymous referees for their valuable comments and suggestions. Any re-
maining errors are my own.

Joanna Mackiewicz-Lyziak, Assistant Professor at the Department of Macroeconomics and International Trade, Faculty of Economic Sciences, Warsaw University, Warsaw, Poland.

E-mail: jmackiewicz@wne.uw.edu.pl 


\section{INTRODUCTION}

Credibility is commonly defined as the ability of monetary authorities to manage inflationary expectations. Theoretical considerations lead to the conclusion that if the inflation expectations of economic agents are high, the process of disinflation tends to be longer and more costly in terms of output loss. Hence, a central bank (CB) that can manage inflation expectations should be able to conduct a more effective monetary policy. However, this theoretical claim has proved to be difficult to verify empirically because credibility is a qualitative concept, which does not lend itself readily to measuring. The present study proposes a comprehensive index of $\mathrm{CB}$ credibility with the aim to facilitate empirical work in that area.

To date, empirical studies attempting to measure $\mathrm{CB}$ credibility have relied on one of two approaches: either a quantification of credibility determinants (credibility creation approach) or a quantification of credibility effects (credibility impact approach). The first method selects and quantifies a factor that, according to a commonly accepted view, influences CB credibility. For instance, in a number of studies, $\mathrm{CB}$ independence was used as a proxy of credibility. However, such a measure may not be fully reliable because credibility, as a multidimensional phenomenon, may be influenced by many other determinants. Moreover, characteristics such as independence are relatively stable, in contrast to credibility, which is considered to change gradually over time.

According to the second approach, CB credibility is measured on the basis of variables which are influenced by credibility. These variables include inflationary expectations and long-term interest rates. For some countries, especially less developed and transition economies, problems may arise with the availability of data. To obtain reliable data on long-term interest rates, well-developed financial markets are needed, a condition that is not fulfilled in many countries. As far as inflationary expectations are concerned, a possible heterogeneity of the expectations of various groups of economic agents results in the need to make a decision on whose expectations to analyse in this context.

This study makes use of the first of these approaches, the credibility creation approach, and encompasses the main determinants of CB credibility. The remainder of the paper examines the components of the credibility index in detail, and is organised as follows. Section 2 provides an overview of the literature investigating the determinants of CB credibility. Section 3 describes the detailed structure of the credibility index; Section 4 presents compiled index values for the 9 countries covered by the study and then proceeds to compare the obtained results (developed indices) with credibility measures that, by contrast, use the credibility impact approach. Finally, the last section offers some conclusions. 


\section{DETERMINANTS OF CENTRAL BANK CREDIBILITY}

The construction of the credibility index is based on the quantification of the main determinants of the $\mathrm{CB}$ credibility. In this study, results of a widely cited survey conducted by Blinder (2000) constituted a starting point. Respondents were invited to provide their opinions on how a CB can build or create credibility. Respondents indicated a history of honesty (a history of living up to its word), independence, and a history of fighting inflation as the most significant features. A not much lower score was assigned to the transparency of monetary policy and a small fiscal deficit or debt. However, some factors that the theoretical literature and empirical studies consider important were omitted from the survey. Aiming to amend that, the present paper addresses an additional factor: the accountability of a CB.

The transparency of monetary policy is regarded as a matter of great importance in the literature and in the practice of modern central banking, in particular in the inflation targeting framework. The relationship between transparency and credibility was discussed in several important articles, including Cukierman Meltzer (1986), Faust - Svensson (2001), Geraats (2001) and Jensen (2002). The general conclusion is that a higher degree of transparency is beneficial for CB credibility. Transparency makes it easier for the private sector to infer the true intentions of the monetary policymakers. As such, transparency makes the expectations of the economic agents more sensitive to actions of the CB. Hence, a $\mathrm{CB}$ that cares about its reputation becomes less willing to create inflationary surprises. Lately, Vayid (2013) interpreted forward guidance as a link between $\mathrm{CB}$ communication and credibility. Forward guidance is used by $\mathrm{CBs}$ as a tool for managing the expectations of financial markets and the public.

The empirical verification of the relationship suggested by the theoretical literature is difficult, because both concepts - transparency and credibility - are difficult to measure. However, the creation of some transparency indices (e.g. Fry et al. 2000; Chortareas et al. 2002; Eijffinger - Geraats 2006) enabled studies concerning the relationship between transparency and other macroeconomic variables. A link between transparency and credibility is suggested by several studies, including Cecchetti - Krause (2002), Levin et al. (2004), van der Cruisen - Demertzis (2005), Geraats et al. (2006), and Gürkaynak et al. (2006).

The second feature, independence, is commonly regarded as one of the most important conditions for a CB to be credible. Debate on this issue was initiated by Rogoff (1985). According to Rogoff's model, the appointment of an independent, conservative central banker should lead to a reduced inflation bias. The beneficial role played by independence was evidenced by Alesina - Summers (1993), de Haan - Kooi (1997), and Eijffinger et al. (1998). However, Fuhrer (1997) 
found no evidence for the "credibility bonus" of the independent CB. No relationship between independence and credibility was found by Posen (1998) either. In his famous study, he tested several hypotheses that could be empirically verified and found no evidence that greater independence leads to greater credibility.

Recently, the global financial crisis caused increased interest in linkage between CB independence and credibility. For example, Blinder (2012) claims that in a crisis, $\mathrm{CB}$ independence is neither possible nor desirable, and what is needed is coordination between monetary and fiscal authorities. On the other hand, Borrio (2011) underlines the need for stronger operational independence to ensure the ability of $\mathrm{CBs}$ to fulfil their tasks in post-crisis times. Despite some controversies concerning the relationship between $\mathrm{CB}$ independence and $\mathrm{CB}$ credibility, it seems to be a commonly accepted view in macroeconomics that independence is an important condition for $\mathrm{CBs}$ to be credible to economic agents. Consequently, independence has been included as a component of the credibility index.

CB transparency and independence are inseparably connected with CB accountability. While academic considerations regarding accountability focus mainly on the role of institutions in democratic societies, they also lead to questions about a possible impact of accountability on monetary policy outcomes and credibility of monetary policymakers. If monetary policy is conducted by an independent institution that is chaired by individuals who have not been elected in a democratic manner, such persons should be held accountable for their actions. Hence, accountability may be viewed as an important factor improving the quality of monetary policymaking. Accountability may be analysed in the following three aspects: (1) decisions about the explicit definition and ranking of objectives of monetary policy, (2) transparency of actual monetary policy, and (3) question of who bears final responsibility with respect to monetary policy, with transparency discussed separately in this study.

With respect to the third aspect of accountability, the final responsibility for monetary policy, Eijffinger - Hoeberichts (2002) show that if the final responsibility shifts in the direction of the government, inflationary expectations increase. As a result, the credibility of monetary policy is lower. Nevertheless, it seems to be generally agreed that to legitimise the central banks' actions, some kind of democratic control over the CB should be established. Most commonly, such control is implemented through the requirement to report or explain policy actions to the Parliament or the government, but it is also possible to employ some forms of overriding mechanisms or dismissal procedures for the $\mathrm{CB}$ governor.

A history of honesty has been interpreted in this paper as the conducted policy being in accordance with the announced goals of monetary policy. This is the most intuitive way of gaining credibility. If the $\mathrm{CB}$ sets inflation targets, to pursue and achieve them in a consistent manner is but a natural way leading to anchoring 
inflationary expectations in the inflation target. Empirical studies confirm that the announcement of an inflation target helps anchor inflation expectations at desired level (e.g. Demertzis et al. 2009). A history of honesty has been ranked first by both central bankers and academics in Blinder's survey concerning ways of building credibility. Another factor ranked high in that survey, the history of fighting inflation, may seem very close to a history of having successfully achieved inflation targets. In practice, in many countries it may be virtually the same, but conceptually these two issues should be distinguished. The importance of low past inflation for building credibility is stressed in the early theoretical literature. Past inflation record is the key issue in reputation models (e.g. Barro - Gordon 1983; Backus - Driffil 1985). ${ }^{1}$

The credibility determinants discussed above are directly connected with the institutional arrangements concerning the $\mathrm{CB}$, or related to the way in which monetary policy is conducted. Still, there may be other factors that influence the credibility of monetary policy, but they are beyond the CB's direct control. One such factor has been included in the study: public debt. Fiscal policy stance was indicated as one of the determinants of credibility in the Blinder's survey. There is ample literature investigating the link between public debt and inflation, following the discussion initiated by the famous "unpleasant monetarist arithmetic" by Sargent - Wallace (1981) and followed by the fiscal theory of the price level (Woodford 1994, 1995, 1996, 1998, 2001; Leeper 1991; Sims 1994; Cochrane 2000, 2001). The authors demonstrate that in the environment marked by fiscal dominance and high public debt, the monetary authorities eventually lose control over inflation. Inflationary pressures caused by high debt undermine the credibility of monetary policy. On the other hand, Reinhart - Sack (2000) argue that low public debt should help keep inflation expectations low.

More recently, the issue of credibility has been discussed in the context of monetary policy after the global financial crisis. Until then, the common wisdom said that the best what CBs could do for the economy was to maintain price stability. Now it seems that there is no consensus on what CBs can and should achieve. Practitioners and theorists of monetary policy realised that price stability is not sufficient to guarantee economic and financial stability. Borrio (2011) writes about the "paradox of credibility", arguing that low and stable prices and high level of CB credibility (reflected in low and stable inflationary expectations) made it harder to recognise increasing disequilibrium in the economy because it did not show up in rising inflation, but in increasing credit and asset

The importance of the past inflation record is especially visible for EMU countries with one central bank pursuing the same inflation target. Cruisen - Demertzis (2011) show that for some EMU countries, their inflation experiences still affect national inflation expectations. 
prices. Moreover, the unconventional measures used by CBs after the outburst of the global financial crisis (quantitative easing and credit easing) and the reorientation in monetary policy made the public unsure of what the true goals of CBs were and what the outcomes of such policies would be. Monetary policymakers realise that and try to manage the markets and the public expectations using, for example, forward guidance. Increased openness and communication should also help economic agents infer the true priorities of CBs. On the other hand, a complicated picture of modern monetary policy makes it harder to assess CB credibility.

\section{THE INDEX FOR CENTRAL BANK CREDIBILITY}

The suggested credibility index consists of 6 sub-indices and each sub-index is based on one of the determinants of credibility described in the previous section. Each of the composite factors has been quantified in such a manner that it ranges from 0 (no credibility) to 100 (full credibility).

\subsection{Achievement of announced monetary policy targets}

In Blinder's survey, respondents identified a history of "doing what the central bank said it would do" as the main factor contributing to the CB's credibility. In cases where publicly announced monetary policy targets exist, this factor may be assessed by the degree to which the targets have been achieved. In this study, the assessment has been twofold: as the scope of time in which the target variable (inflation) remained within the announced target boundaries, and as the size of deviations of inflation from the target.

The reason for assessing the meeting of targets in such a way is that CBs may set inflation targets in various manners. Naturally, in terms of credibility, it is important how often the CB has achieved its targets. But it also seems to matter for credibility whether inflation targets were missed with a wide target range (e.g. in Brazil) or with a point target (initially in Chile). Moreover, it is rather larger deviations of inflation from the target than smaller ones that are likely to have a greater impact on credibility.

The scope of time in which inflation targets were met is expressed as the percentage of months in the year in which inflation remained within the target bounds. In cases where there were only short-term inflation targets set for the end of subsequent years, the targets have been interpolated to obtain target values for 
each month. ${ }^{2}$ If the short-term targets were subject to change during a year, $25 \%$ of the index value has been subtracted in order for a possible negative impact of such occurrences on $\mathrm{CB}$ credibility to be taken into account. ${ }^{3}$

The second element in the assessment of accuracy in hitting inflation targets is the size of deviations of inflation from the target. To be incorporated in the credibility index, the deviations are transformed with the use of the following formula:

$$
\frac{100}{e^{0.5|\operatorname{lin} f-\operatorname{tar}|}}
$$

where inf stands for inflation and tar for the target set for the corresponding period. ${ }^{4}$

The transformation is designed in such a way that for inflation on the target level, the sub-index amounts to 100 , which is the maximum value. When the deviations of inflation from the target increase, the function converges non-linearly to 0.5

The two discussed elements taken into account while assessing the realisation of the targets by CBs are included with equal weights. Hence, the first part of the credibility index may be presented as the following function:

$$
C I_{1}=0.5 \cdot(\% \text { of time })+0.5 \cdot \frac{100}{e^{0.5|\operatorname{lnf}-\operatorname{tar}|}}
$$

2 With regard to the variety of solutions within the inflation targeting framework in various countries, the method of calculating the index has been adapted to these individual solutions. For instance, in Chile point inflation targets have been set for some years. In this study, the target was considered to be met if inflation did not deviate from the target by more than $+/-0.2$ p.p. In Turkey, for most of the period under consideration, the target was unsymmetrical, so the target was considered to be met if inflation was below target. In Slovakia, targets were set for several inflation indices: CPI for the end of the year, yearly average CPI and net inflation. In order to obtain monthly targets, the following transformation has been adopted: $\operatorname{tar}_{i}=a i^{2}+b i$ $+c$, where $c=\operatorname{tar}_{0}$ and $\frac{1}{12} \sum_{i=1}^{12} \operatorname{tar}_{i}=\operatorname{ta} \bar{r}_{1}$ (where $t a r_{i}-$ target for the $i$ th month of year, $\operatorname{tar}_{0}-$ target for the end of the previous year, and $t a r_{12}$ - target for the average yearly inflation).

3 This was the case in Slovakia in 2000, in Poland in 1999 and 2002, and in Brazil in 2003 (inflation target changes).

4 A similar formula was used by Kia - Patron (2004) to measure the transparency of the US monetary policy.

5 In the case of Hungary, the deviations from the target were calculated only for inflation targets, although the scope of time, when policy targets were met, was calculated for inflation being within the target band as well as the exchange rate being within the exchange rate band (with weights equal to 0.5 ). The first inflation target was set for $2001 \mathrm{r}$. However, in previous years, the exchange rate policy (maintaining the exchange rate band) was shaped in such a manner as to achieve a preferred inflation rate. In this study, it has been assumed that this preferred inflation rate was the inflation rate foreseen in the budget plan. These values were used for calculation for the years in which no explicit inflation targets were set $(1999,2000)$. 


\subsection{Past inflation performance}

The past inflation record is undoubtedly one of the most important factors that influence CB credibility. Monetary authorities who are capable of conducting disinflation successfully or of stabilising inflation at low levels will probably enjoy higher credibility. Nevertheless, inflation is driven not only by domestic factors. Therefore, to allow for price changes on the global markets without affecting the credibility index, past inflation rates have been expressed in the index in relation to inflation in advanced economies, where inflation is relatively low and stable. ${ }^{6}$

Thus, the second sub-index of the credibility measure has the following form:

$$
C I_{2}=\left\{\begin{array}{lc}
0 & \text { for } \bar{\pi}_{t} \geq 20 \% \\
100-\frac{100}{20-\bar{\pi}_{t}^{\text {devel }}}\left(\bar{\pi}_{t}-\bar{\pi}_{t}^{\text {devel }}\right) & \text { for } \bar{\pi}_{t}^{\text {devel }}<\bar{\pi}_{t}<20 \% \\
100 & \text { for } \bar{\pi}_{t} \leq \bar{\pi}_{t}^{\text {devel }}
\end{array}\right.
$$

where: $\bar{\pi}_{t}$ denotes the average inflation in a given country during the past three years and $\bar{\pi}_{t}^{\text {devel }}$ the average inflation rate in advanced economies during the past three years.

The sub-index $\mathrm{CI}_{2}$ amounts to 0 if the average inflation during past three years exceeded $20 \%$, and to 100 if the average inflation was lower than average inflation during the past three years in developed countries. In other cases, the credibility negatively depends on the difference between average past inflation in the given country and average past inflation in advanced countries. At the same time, it is assumed that a higher rate in the average inflation in advanced economies will result in a stronger impact of the inflation difference on credibility. ${ }^{7}$

6 According to the classification of the IMF. Data on the average inflation rate in advanced economies from the World Economic Outlook of the IMF were used for the compilation of the sub-index.

7 A function of this form designed to assess CB credibility was used by Cecchetti - Krause (2000). In their study, inflation expectations were used instead of country-specific past inflation, while the inflation target was used in place of past inflation in developed countries. They also assumed that with inflation expectations higher than $20 \%$, the CB has no credibility.The authors assumed that inflation expectations were equal to average inflation during the past 5 years. Hence, in this study, a threshold of $20 \%$ average inflation was also assumed, above which the central bank has no credibility. Of course, this assumption is arbitrary, but it seems consistent with intuition. 


\subsection{Transparency of monetary policy}

Transparency has become a focal point for inflation targeting strategies implemented by a considerable number of CBs. It is a qualitative characteristic, and thus one which is not easy to measure. In this study, transparency is quantified with the use of the index proposed by Fry et al. (2000). It is a comprehensive index, capturing all important aspects of transparency. Moreover, the same authors invented also the independence and accountability indices used in this study, the implication being that these measures should be relatively consistent.

For the aims of this study, separate transparency indices have been compiled for each country on an annual basis. Hence, the third component of the credibility index is rendered as follows:

$$
\mathrm{CI}_{3}=\text { transparency } \text { index }^{8}
$$

\subsection{Central bank independence}

According to the view prevalent in the economic literature, $\mathrm{CB}$ independence is another characteristic that has profound effects on credibility. As is the case with transparency, independence has been quantified using the method developed by Fry et al. (2000).

$$
\mathrm{CI}_{4}=\text { independence index }
$$

The independence index proved much more stable than the transparency index, for most countries in the sample guaranteed the CBs formal independence before 1999. It should be noted that the independence index measures the independence de jure, while there might be some more significant changes in the independence de facto. The independence de facto is much more difficult to measure, so the most known and widely used independence indices measure the independence de jure.

\subsection{Central bank accountability}

The feature that is strongly linked to the CB's transparency and independence is the bank's accountability. The reason for implementing means to enhance transparency and accountability is the widespread belief that independent institutions in democratic societies need some form of democratic control.

In the study, the same weights and scores are used as in the original questionnaire by Fry et al. (2000). The weights of each question and the scores attached to each answer in the questionnaire are not explicitly explained by the authors. 
As already mentioned, CB accountability is quantified with the use of the accountability index constructed by Fry et al. (2000). However, the original index has been modified slightly, since there was one area in which it was found to overlap with the independence index. Specifically, both the independence index and the original accountability index intended to capture the role of the government in setting the inflation target. The government's participation in deciding the inflation target lowers independence but increases accountability. It may be argued that $\mathrm{CB}$ credibility, particularly in less developed countries, tends to be enhanced when it is only the CB that sets inflation targets. Consequently, the accountability index has been modified to remove that issue from the scope of the index.

$$
C I_{5}=\text { accountability index }
$$

\subsection{Public debt}

The last component of the credibility index is a sub-index for public debt. As already pointed out, the larger the public debt, the higher the expectations for future inflation, or, in other words, the lower the perceived ability of the CB to control inflation, resulting in losing some of its credibility. Since credibility is negatively correlated to the value of the public debt figure, the following formula is used to secure the relationship and transform it in such a way that the sub-index falls within the range from 0 to 100 :

$$
C I_{6}=\left\{\begin{array}{lll}
0 & \text { if } & \frac{d e b t}{G D P} \cdot 100>100 \\
100 \cdot\left(1-\frac{d e b t}{G D P}\right) \cdot \frac{10}{4} & \text { if } & 60 \leq \frac{d e b t}{G D P} \cdot 100 \leq 100 \\
100 & \text { if } & \frac{d e b t}{G D P} \cdot 100<60
\end{array}\right.
$$

where debt stands for the general government debt.

While designing the sub-index, it was assumed that a level of public debt lower than $60 \%$ of GDP does not harm the CB's credibility (this is the maximum level of public debt to GDP ratio that is considered to be "safe" and not to undermine the ability of common CB to maintain price stability in the Stability and Growth Pact). In contrast, a level of public debt higher than $100 \%$ of GDP 
is assumed to be so significant that the sub-index is equal to zero. ${ }^{9}$ For the public debt in ranges from $60 \%$ to $100 \%$ of GDP, the credibility depends linearly on debt.

\subsection{The weights}

The credibility index presented in this study consists of six sub-indices. However, the six determinants of credibility reflected by the sub-indices may influence credibility with different strength. Hence, the weights on respective sub-indices have been differentiated accordingly. The strength with which the particular attribute affects credibility has been proxied by the average score of the attribute given by the respondents in Blinder's survey. The scores given by economists have been adopted as a basic variant. The weight of each sub-index is the relation of the average score of the given factor to the sum of the average scores of all factors considered. Since Blinder's survey fails to include CB accountability, an assumption has been made that the weight of accountability is equal to the weight of the transparency of monetary policy. All the weights sum up to unity.

$$
\begin{aligned}
C I=0.19 \cdot C I_{1}+0.17 \cdot C I_{2} & +0.155 \cdot C I_{2}+0.18 \cdot C I_{4}+0.155 \cdot C I_{5}+ \\
& +0.15 \cdot C I_{6}{ }^{10}
\end{aligned}
$$

\section{CREDIBILITY INDEX - RESULTS}

We attempted to quantify the credibility of CBs in four CEE countries - the Czech Republic, Hungary, Poland, and Slovakia as an illustration of the proposed measure of credibility. All these countries adopted inflation targeting (IT) as a frame-

9 There are no precise estimates on what level of public debt may cause fiscal dominance and lead to the situation in which the price level will have to adjust in order to satisfy the government's intertemporal budget constraint. In this study, the perception of the public is regarded as important - what level of debt people would consider "too high" and potentially dangerous. It is more probable that the public will notice change in the level of public debt from $99 \%$ of GDP to $100 \%$ of GDP than from $89 \%$ of GDP to $90 \%$ of GDP. For this reason, the value of $100 \%$ of GDP has been assumed for the aims of the study.

10 In order to check the sensitivity of the index to a change of the weight system, four alternative weight systems have been adopted. The ranking of the countries according to the average credibility index in the period 1999-2007 is the same in three out of four variants (including the basic variant). A more detailed analysis (not reported in this paper) proved that the index is sensitive to a change of weights only to a very limited extent. The analysis is available from the author upon request. 
work for monetary policy during the transition period with the goal of stabilising inflation and inflation expectations, and it seems that this framework proved to be quite successful. For comparison, we also computed the values of the index for three emerging economies: Brazil, Chile and Turkey, and two advanced economies, Sweden and the UK. All these countries also used IT as a framework in monetary policy. ${ }^{11}$

A variety of data is needed for the compilation of the credibility index. Transparency, independence, and accountability were quantified on the basis of Fry et al. (2000) and central banks' documents, publications, and information available on the central banks' websites. Central banks' websites are also sources of data on inflation targets. The source of data on inflation rates are countries' statistical offices, and the average inflation rate in advanced economies used for computation of the past-inflation sub-index comes from the IMF World Economic Outlook database. Data on general government debt to GDP ratio in European countries and Turkey ${ }^{12}$ comes from Eurostat, for Brazil from the Central Bank of Brazil, and for Chile from the Direccion de Presupuestos (DIPRES).

The results of the compiled credibility index for the nine countries in the period 1999-2007 are presented in Table 1 in Appendix 1. The sample ends in 2007, so it does not include the financial crisis period. The reason for this was to demonstrate the performance of the credibility index in "normal" times, given the lack of consensus on monetary policy in the post-crisis period in terms of its goals (price stability $v s$. financial stability) and instruments, as described in Section 2. In this situation, the comparison of the credibility index with other credibility measures - as presented below - may be misleading. ${ }^{13}$

On the basis of the results it may be stated that the credibility expressed by the credibility index generally increased in the period under consideration in the analysed countries. The most significant change between the year 1999 and 2007 was recorded for the Central Bank of Turkey, whereas the most stable index values were noted for the Bank of England. Mainly three factors contributed to the overall increase in the credibility index: past inflation, effectiveness in hitting inflation targets, and transparency of monetary policy. These changes reflect the success of inflation targeting in these countries, as the CBs were able to control inflation better and be more precise in hitting inflation targets.

11 The reason for choosing only inflation targeters for the study was to cross-check the results with credibility measures based on inflation expectations and inflation targets.

12 For Turkey, the time series begins in 2000, so the value for 1999 comes from the IMF.

13 Another point is, as Blinder (2012) argues, that building central bank credibility in a crisis may require different actions than in normal times; for example, providing low inflation may not be a condition for the central bank to be credible. 
A significant increase could be noted in the transparency of monetary policy in the analysed countries. All the CBs in the sample improved their transparency in this period. The most considerable improvement was achieved in the aspect of transparency concerning the publication of macroeconomic forecast and forward-looking analyses.

The other factors changed to a considerably lesser extent. CB independence did not change much because by 1999 , most of the CBs in the sample had already implemented the most important reforms in this field. None of the CBs had full independence according to the independence index, yet they had a high degree of independence. In 2007, the Central Bank of Brazil was least independent, whereas the Riskbank in Sweden was most independent. Also, the National Bank of Poland, the Czech National Bank, and the National Bank of Slovakia were granted a high degree of formal independence.

Accountability was the factor that was least variable during the analysed period. All the CBs announced numerical policy targets and all were subject to some form of parliamentary or governmental monitoring. The only difference between the countries could be noticed in the existence of formal procedures to be executed if targets were missed. Such procedures existed in Brazil, Sweden, Turkey, and the UK. Also, only slight changes were noted in the factor exogenous to monetary policy, namely public debt. During the sample period, the analysed countries were not heavily indebted, with public debt to GDP ratio below $60 \%$ of GDP in most of them. At the end of the sample period, the public debt was higher than $60 \%$ of GDP only in Hungary.

\subsection{Comparison with other measures of central bank credibility}

In the introduction, we referred to the credibility measures based on long-term interest rates or the inflation expectations of economic agents. As the concept of credibility refers to the public's beliefs about the $\mathrm{CB}$ willingness or ability to pursue the certain policy, these measures seem to be a natural choice when analysing credibility. Moreover, some of them have the advantage that they allow for observing the gradual evolution of credibility in time. For example, Goldberg - Klein (2011) study the credibility of the European Central Bank by analysing changes of the effects of news announcements on the yield curve for euro area countries, using hourly data. However, the use of such measures is limited due to the availability and quality of data, especially for the less developed economies.

In order to check the correctness of the proposed index, the obtained values of the credibility index have been compared to results obtained using credibility measures based on the inflation expectations of economic agents. Credibility 
measures based on inflation expectations are calculated with the use of a quite different set of variables from those employed in the proposed credibility index, so it seemed interesting to compare their results. Two measures based on inflation expectations suggested in the theoretical literature have been calculated: the deviations of inflation expectations from the inflation target (e.g. Faust - Svensson 2001), and the weight of the inflation target in the formation of inflation expectations (e.g. Bomfim - Rudebusch 2000).

Inflation expectations may be different depending on the analysed group of agents. For this reason, the above-mentioned measures have been calculated for two groups of agents: financial analysts and consumers. However, the data are not homogeneous for all the countries, so it complicates conclusions to some extent. Moreover, the data on consumer inflation expectations were not available for some countries (including Brazil, Chile, and Turkey in this study). Data source of financial analysts' expectations are the countries' central banks (Brazil, Chile, the Czech Republic, Slovakia, Sweden, Turkey, and the UK) and Reuters (the Czech Republic for net inflation, Hungary, and Poland). The data is monthly, with the exception of Sweden and the UK, which are quarterly. Data on consumers' inflation expectations in the Czech Republic, Hungary, Slovakia, and the UK come from the European Commission Consumer Survey and were quantified by Łyziak - Stanisławska (2008), for Poland the data source is NBP, and for Sweden it is the National Institute of Economic Research. All the data is monthly.

\subsubsection{The credibility index and the deviations of inflation expectations from the inflation target}

The comparison of the credibility index and the deviations of inflation expectations from the inflation target is based on correlations between these two credibility measures. Since the number of observations was low for the respective countries, the correlations have been calculated jointly for all the countries. The deviations of inflation expectations from the inflation target may be computed in several ways. In this study, the following deviation measures have been used:

- the absolute deviations of inflation expectations from the inflation target (yearly average) - as the simplest credibility measure, consistent with definition of credibility,

- the absolute deviations of inflation expectations from the inflation target relative to the target (yearly average) - a measure used to facilitate the comparison between individual countries,

- the absolute deviations of inflation expectations, smoothed by the HodrickPrescott filter, from the inflation target (yearly average) - a measure used 
Table 1. Correlations of the credibility index with respective measures of deviations of inflation expectations from the inflation target

\begin{tabular}{l|c|c}
\hline \multirow{2}{*}{$\begin{array}{l}\text { Deviation } \\
\text { measure }\end{array}$} & \multicolumn{2}{|c}{ Group of agents } \\
\cline { 2 - 3 } Dev. & Analysts & Consumers \\
Prob. & $\mathbf{- 0 . 6 1} * * *$ & $\mathbf{- 0 . 6 1} * * *$ \\
\hline Dev./tar. & 0.00 & 0.00 \\
Prob. & $-\mathbf{0 . 5 4} * * *$ & $-\mathbf{0 . 3 9} * * *$ \\
\hline Dev. HP & 0.00 & 0.01 \\
Prob. & $\mathbf{- 0 . 6 6} * * *$ & $-\mathbf{0 . 5 0} * * *$ \\
\hline Dev. HP/tar & 0.00 & 0.00 \\
Prob. & $-\mathbf{0 . 6 0} * * *$ & $-\mathbf{0 . 2 3}$ \\
\hline Number of observations & 0.00 & 0.10 \\
\hline
\end{tabular}

Note: In the case of consumers, only data for European countries from the sample were available, so the number of observations is lower.

Dev. - absolute deviations of inflation expectations from the inflation target, Dev./tar. - absolute deviations of inflation expectations from the inflation target relative to the target, Dev. HP - absolute deviations of inflation expectations, smoothed by the Hodrick-Prescott filter, from the inflation target, Dev. HP/tar. - absolute deviations of inflation expectations, smoothed by the Hodrick-Prescott filter, from the inflation target relative to the target; *** significant at the $1 \%$ level.

Source: Own calculations.

because in the case of a few countries, only short-term inflation expectations were available, which may be sensitive to transitory shocks,

- the absolute deviations of inflation expectations, smoothed by the HodrickPrescott filter, from the inflation target relative to the target (yearly average). All the deviations have been calculated from the centre of the target range.

Table 1 presents the correlation of the credibility index with all the abovelisted measures of deviations of the inflation expectations of two groups of agents from the inflation target. The study considered only inflation targets that were known at the time of forming the inflation expectations and that were set for the time horizon for which the expectations were formed.

The results show that the correlation between the credibility index and the deviations of inflation expectations from the inflation target is strong, negative, and statistically significant. It should be noted that the correlation is stronger in the case of the expectations of financial analysts than it is in the case of consumer expectations. However, all the results obtained confirm a significant relationship. The smaller the deviations of inflation expectations from the inflation target, in- 
dicating higher credibility, the higher the credibility index. ${ }^{14}$ The results suggest that the analysed credibility measures are consistent.

\subsubsection{The credibility index and the weight attached to the inflation target in the formation of inflation expectations by economic agents}

The theoretical considerations suggest that the higher the $\mathrm{CB}$ credibility, the more the economic agents should be convinced that the announced inflation target would be met. Consequently, the weight of the inflation target in forming inflation expectations should be higher. In order to assess the weight of the inflation target, the following equations of inflation expectations have been estimated:

$$
\pi_{T \mid t}^{e}=a_{1} \cdot \pi_{T}^{t a r}+a_{2} \cdot \pi_{t}^{0}+a_{3} \cdot \operatorname{gap}_{t-2}+a_{4} \cdot \Delta e_{t}^{15}
$$

where $\pi_{T \mid t}^{e}$ stands for inflation expectations formed at time $t$ for period $T, \pi_{T}^{\text {tar }}-$ inflation target for period $T$, known at the moment of forming expectations, $\pi_{t}^{0}$ - inflation rate known at time $t$, gap $_{t-2}$ - unemployment gap at time $t-2^{16}$, and $\Delta e_{t}$ - nominal exchange rate percentage change. ${ }^{17}$

$$
\pi_{T \mid t}^{e}=\lambda \cdot \pi_{T}^{t a r}+(1-\lambda) \cdot \pi_{t}^{0}
$$

As in the previous case, the inflation expectations of the two groups of agents, financial analysts and consumers, have been used. In this case, the credibility

14 In order to verify the robustness of the results, apart from the Pearson correlation coefficient (which assumes the linear relationship), the Spearman rank correlation coefficient has been calculated (not reported in this paper). The results for the financial analysts' expectations were very similar to those obtained in the case of the Pearson correlation. The Spearman rank correlation was lower than the Pearson correlation in the case of consumer inflation expectations, but was still quite high.

15 Such specification of inflation expectations equation was used for Brazil by Bevilaqua et al. (2007).

16 The unemployment gap was calculated using the Hodrick-Prescott filter. Only in the case of Brazil was the equation estimated with the output gap because of the lack of consistent data for unemployment in the whole period. The output gap was calculated by filtering the output data with the Hodrick-Prescott filter. The data source for the Czech Republic, Hungary, Poland, Slovakia, Sweden, and the UK is Eurostat, for Brazil, Chile and Turkey, the countries' statistical offices.

17 In order to avoid excessive volatility, the nominal exchange rate percentage change during 6 months has been calculated. In the case of European countries (except for the UK), the exchange rate of euro to domestic currency was used, while in the case of the remaining countries the US dollar exchange rate. 
measure to be compared with the credibility index is the coefficient on the inflation target in estimated equations. An increase in the coefficient value can be interpreted as an increase in credibility. Additionally, the coefficient on past inflation may be observed. A decrease in the coefficient value indicates that the expectations become less adaptive, which may also be a sign of higher credibility.

In order to allow for a change in the coefficients, the equations have been estimated using the 36-month rolling window regressions. The exemplary results are presented below: ${ }^{18}$

\section{Results of estimation of equation (9)}

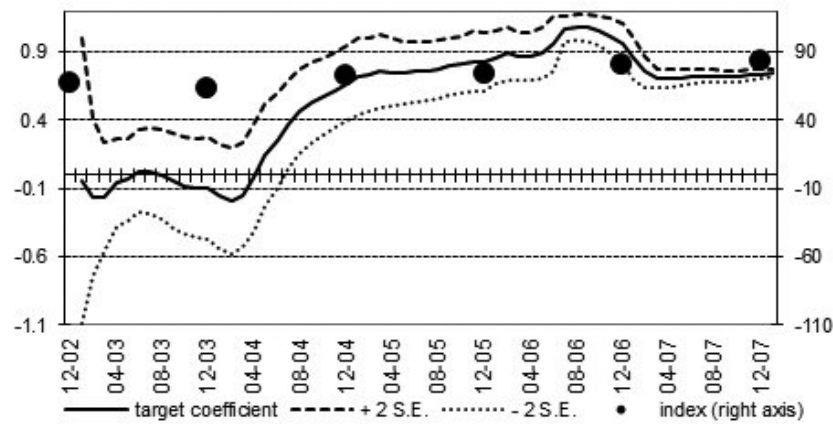

Figure 1. Coefficient on the inflation target in the equation of analysts' inflation expectations in Brazil

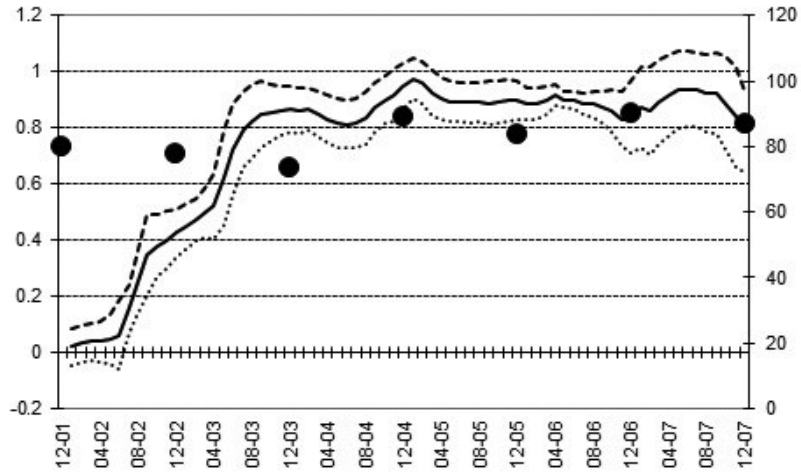

Figure 2. Coefficient on the inflation target in the equation of analysts' inflation expectations in the Czech Republic

18 The figures represent an estimated coefficient and a band of $+/-2$ S.E. The coefficient on the inflation target is compared to the credibility index in the corresponding time period. The rest of the results - coefficients on inflation targets in equations (9) and (10) - are presented in the tables in Appendix 2. All remaining figures, including coefficients on past inflation in inflation expectations equations, are available upon request from the author. 
2. Results of estimation of equation (10)

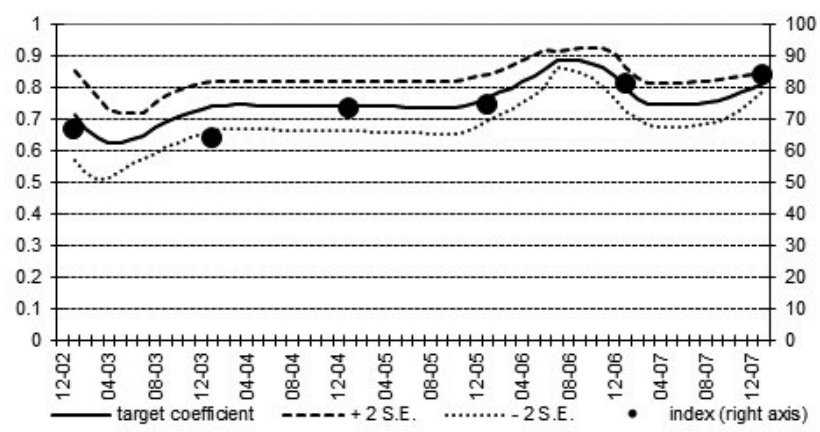

Figure 3. Coefficient on inflation target in equation of analysts' inflation expectations in Brazil

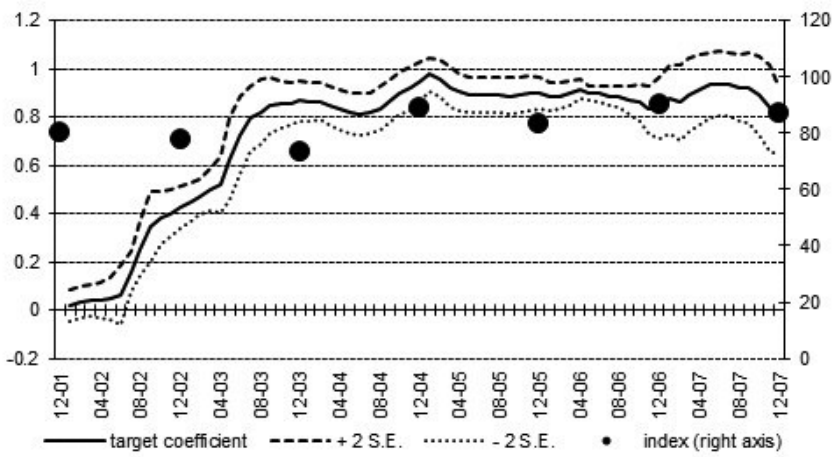

Figure 4. Coefficient on the inflation target in the equation of analysts' inflation expectations in the Czech Republic

Our obtained results lead to two important conclusions. Firstly, there are noticeable differences between the inflation expectations of the two groups of economic agents: financial analysts and consumers. In those countries where it was possible to obtain comparable data on the inflation expectations of financial analysts and consumers, the weight of the inflation target in forming inflation expectations was notably higher in the case of financial analysts than in the case of consumers. Consumers were backward-looking to a considerably higher degree and attached a higher weight to past inflation while forming inflation expectations. Hence, it may be concluded that the belief that the CBs would meet their inflation targets was very strong among financial analysts and very weak among consumers (with the exception of the Swedish consumers). Secondly, it seems 
that the two compared credibility measures, namely the credibility index and the weight of the inflation target in forming the inflation expectations, are consistent to a considerable extent. However, it should be mentioned that the comparison has focused on the direction of changes rather than on the levels of the compared variables. Of course, it is very easy to show opposite cases: in the case of Turkey, for example, the coefficient on inflation expectations in equation (9) falls, while the credibility index increases, or in the case of the UK, the coefficient in equation (9) also falls, while the index does not change. However, the number of such cases is rather small and it seems that the credibility index reflects the credibility changes suggested by the changes in the weights of the inflation target in forming inflation expectations, in particular when the financial analysts' expectations are taken into account.

The findings obtained in this study lead to the conclusion that the credibility index and the credibility measures based on the inflation expectations of economic agents are to a large extent consistent and give a similar picture of CB credibility. It should be stressed that the credibility index is a measure based on the credibility creation approach, while the other measures (the deviations of inflation expectations from the inflation target and the weight attached to the inflation target while forming inflation expectations) are based on the credibility impact approach, so the set of variables used to calculate these measures is entirely different. Taking this into account, it may be stated that the similarities in the results obtained using both the credibility index and the other two credibility measures are sufficient to consider the credibility index to be an appropriate measure of $\mathrm{CB}$ credibility.

\section{CONCLUSIONS}

The results suggest that the credibility index is a relevant and consistent credibility measure. It offers the advantages of being fully comparable between countries and of being time-variant, features that designate it as a suitable instrument in studies that attempt to investigate the macroeconomic effects of CB credibility. The index is also well-founded on theoretical grounds besides being based on the findings of existing empirical studies. Although it may not be treated as a very precise credibility measure, it may be useful for countries where there are no reliable data on inflation expectations or long-term interest rates. As this study shows, the index may be to some extent a substitute for credibility measures based on inflation expectations. The use of the credibility index suggests that the CBs from the sample increased their credibility in the period 1999-2007, especially in the countries where credibility had been low. 
The credibility measure can be used in empirical studies to verify the hypotheses with respect to the credibility of monetary policy formulated in the theoretical literature. Specifically, it is postulated that CB credibility plays a prominent role in macroeconomic processes: it enhances the effectiveness with which monetary policy goals are achieved, reduces disinflation costs, or reduces the trade-off between the inflation volatility and output volatility. To verify these theoretical conceptions empirically might be a viable direction for further research. Moreover, as the credibility index seems to be consistent with other credibility measures based on inflation expectations in "normal" times, the study may be extended for the financial crisis period in order to check whether both types of measures are still consistent with each other or whether they tell us different stories about CB credibility.

\section{REFERENCES}

Alesina, A. - Summers, L. H. (1993): Central Bank Independence and Macroeconomic Performance: Some Comparative Evidence. Journal of Money, Credit and Banking, 25(2): 151-162.

Backus, D. - Driffill, J. (1985): Inflation and Reputation. The American Economic Review, 75(3): 530-538.

Barro, R. J. - Gordon, D. B. (1983): Rules, Discretion and Reputation in a Model of Monetary Policy. Journal of Monetary Economics, 12(1): 101-121.

Bevilaqua, A. - Mesquita, M. - Minella, A. (2007): Brazil: Taming Inflation Expectations. Central Bank of Brazil Working Paper, No. 129.

Blinder, A. S. (2000): Central Bank Credibility: Why do We Care? How do We Build It? The American Economic Review, 90(5): 1421-1431.

Blinder, A. S. (2012): Central Bank Independence and Credibility during and after a Crisis. Griswold Center for Economic Policy Studies Working Paper, No. 229.

Bomfim, A. - Rudebusch, G. (2000): Opportunistic and Deliberate Disinflation under Imperfect Credibility. Journal of Money, Credit and Banking, 32(4): 707-721.

Borrio, C. (2011): Central Banking Post-Crisis: What Compass for Uncharted Waters? BIS Working Papers, No 353.

Calderón, C. - Duncan, R. - Schmidt-Hebbel, K. (2003): The Role of Credibility in the Cyclical Properties of Macroeconomic Policies in Emerging Economies. Central Bank of Chile Working Paper, 237.

Cecchetti, S. G. - Krause, S. (2002): Central Bank Structure, Policy Efficiency, and Macroeconomic Performance: Exploring Empirical Relationships. Federal Reserve Bank of St. Louis Review, 84(4): 47-60.

Chortareas, G. - Stasavage, D. - Sterne, G. (2002): Does It Pay to Be Transparent? International Evidence from Central Bank Forecasts. Federal Reserve Bank of St. Louis Review, 84(4): 99117.

Cochrane, J. (2000): Money as Stock: Price Level Determination with no Money Demand. NBER Working Paper, 7498.

Cochrane, J. (2001): Long-Term Debt and Optimal Policy in the Fiscal Theory of the Price Level. Econometrica, 69(1): 69-116. 
Cruijsen, C. van der - Demertzis, M. (2005): The Impact of Central Bank Transparency on Inflation Expectations. De Nederlandsche Bank Working Paper, No. 31 March.

Cruijsen, C. van der - Demertzis, M. (2011): How Anchored are Inflation Expectations in EMU Countries. Economic Modelling, 28: 281-298.

Cukierman, A. - Meltzer, A. (1986): The Theory of Ambiguity, Credibility, and Inflation under Discretion and Asymmetric Information. Econometrica, 54(5): 1099-1128.

Demertzis, M. - Marcellino, M. - Viegi, N. (2009): Anchors for Inflation Expectations. De Nederlandsche Bank Working Paper, No. 229 November.

Eijffinger, S. C. W. - Geraats, P. (2006): How Transparent are Central Banks? European Journal of Political Economy, 22(1): 1-22.

Eijffinger, S. C. W. - Hoeberichts, M. (2002): Central Bank Accountability and Transparency: Theory and Some Evidence. International Finance, 5(1): 73-96.

Eijffinger, S. C. W. - Hoeberichts, M. - Schaling, E. (1998): Central Bank Independence: A Sensitivity Analysis. European Journal of Political Economy, 14(1): 73-88.

Faust, J. - Svensson, L. E. O. (2001): Transparency and Credibility: Monetary Policy with Unobservable Goals. International Economic Review, 42(2): 369-397.

Fry, M. - Julius, D. - Mahadeva, L. - Roger, S. - Sterne, G. (2000): Key Issues in the Choice of Monetary Policy Framework. In: Mahadeva, L. - Sterne, G. (eds): Monetary Policy Frameworks in a Global Context. London: Routledge.

Fuhrer, J. C. (1997): Central Bank Independence and Inflation Targeting: Monetary Policy Paradigms for the Next Millennium? New England Economic Review, Jan/Feb.: 19-36.

Geraats, P. (2001): Why Adopt Transparency? The Publication of Central Bank Forecasts. ECB Working Paper, No. 41.

Geraats, P. - Eijffinger, S. C. W. - Cruijsen, C. van der (2006): Does Central Bank Transparency Reduce Interest Rates? De Nederlandsche Bank Working Paper, No. 85.

Goldberg, L. - Klein, M. (2011): Evolving Perceptions of Central Bank Credibility: The European Central Bank Experience. In: Clarida, R. - Giavazzi, F. (eds): NBER International Seminar on Macroeconomics. University of Chicago Press, pp. 153-182.

Gürkaynak, R. S. - Levin, A. T. - Swanson, E. T. (2006): Does Inflation Targeting Anchor LongRun Inflation Expectations? Evidence from Long-Term Bond Yields in the U.S., U.K. and Sweden. Federal Reserve Board of San Francisco Working Paper, 2006-09.

Haan, J. de - Kooi, W. (1997): What Really Matters? Conservativeness or Independence? Banca Naziolale Del Lavorno Quarterly Review, 200: 23-38.

Jensen, H. (2002): Optimal Degrees of Transparency in Monetary Policy-Making. Scandinavian Journal of Economics, 104(3): 399-422.

Kia, A. - Patron, H. (2004): Market-Based Monetary Policy Transparency Index, Risk and Volatility - The Case of the United States. Manuscript, Carleton University.

Leeper, E. (1991): Equilibria under Active and Passive Monetary Policies. Journal of Monetary Economics, 27: 129-147.

Levin, A. T. - Natalucci, F. M. - Piger, J. M. (2004): The Macroeconomic Effects of Inflation Targeting. Federal Reserve Bank of St. Louis Review, 86(4): 51-80.

Łyziak, T. - Stanisławska, E. (2008): Consumer Inflation Expectations in Europe: Some CrossCountry Comparisons. National Bank of Poland, Bank and Credit, 9: 14-28.

Mérö, K. (2014): Macroprudential Warning in the Euro Zone and Hungary. Acta Oeconomica, 64(4): 397-417.

Posen, A. S. (1998): Central Bank Independence and Disinflationary Credibility: A Missing Link? Oxford Economic Papers, 50: 335-359. 
Reinhart, V. - Sack, B. (2000): The Economic Consequences of Disappearing Government Debt. Brookings Papers on Economic Activity, 2000(2): 163-220.

Rogoff, K. (1985): The Optimal Degree of Commitment to an Intermediate Monetary Target. The Quarterly Journal of Economics, 100(4): 1169-1189.

Sargent, T. - Wallace, N. (1981): Some Unpleasant Monetarist Arithmetic. Federal Reserve Bank of Minneapolis Quarterly Review, Fall, 1-17.

Sims, C. (1994): A Simple Model for the Determination of the Price Level and the Interaction of Monetary and Fiscal Policy. Economic Theory, 4: 381-399.

Vayid, I. (2013): Central Bank Communications Before, During and After the Crisis: From OpenMarket Operations to Open-Mouth Policy. Bank of Canada Working Paper, 2013-2041.

Woodford, M. (1994): Monetary Policy and Price Level Determinacy in a Cash-in-Advance Economy. Economic Theory, 4: 345-389.

Woodford, M. (1995): Price Level Determinacy without Control of a Monetary Aggregate. Carnegie-Rochester Series on Public Policy, 43: 1-46.

Woodford, M. (1996): Control of the Public Debt: A Requirement for Price Stability? NBER Working Paper, 5684.

Woodford, M. (1998): Comment On Cochrane. NBER Macroeconomics Annual, MIT Press.

Woodford, M. (2001): Fiscal Requirement for Price Stability. Journal of Money, Credit, and Banking, 33(3): 669-728. 


\section{APPENDIX 1}

Values of the credibility index

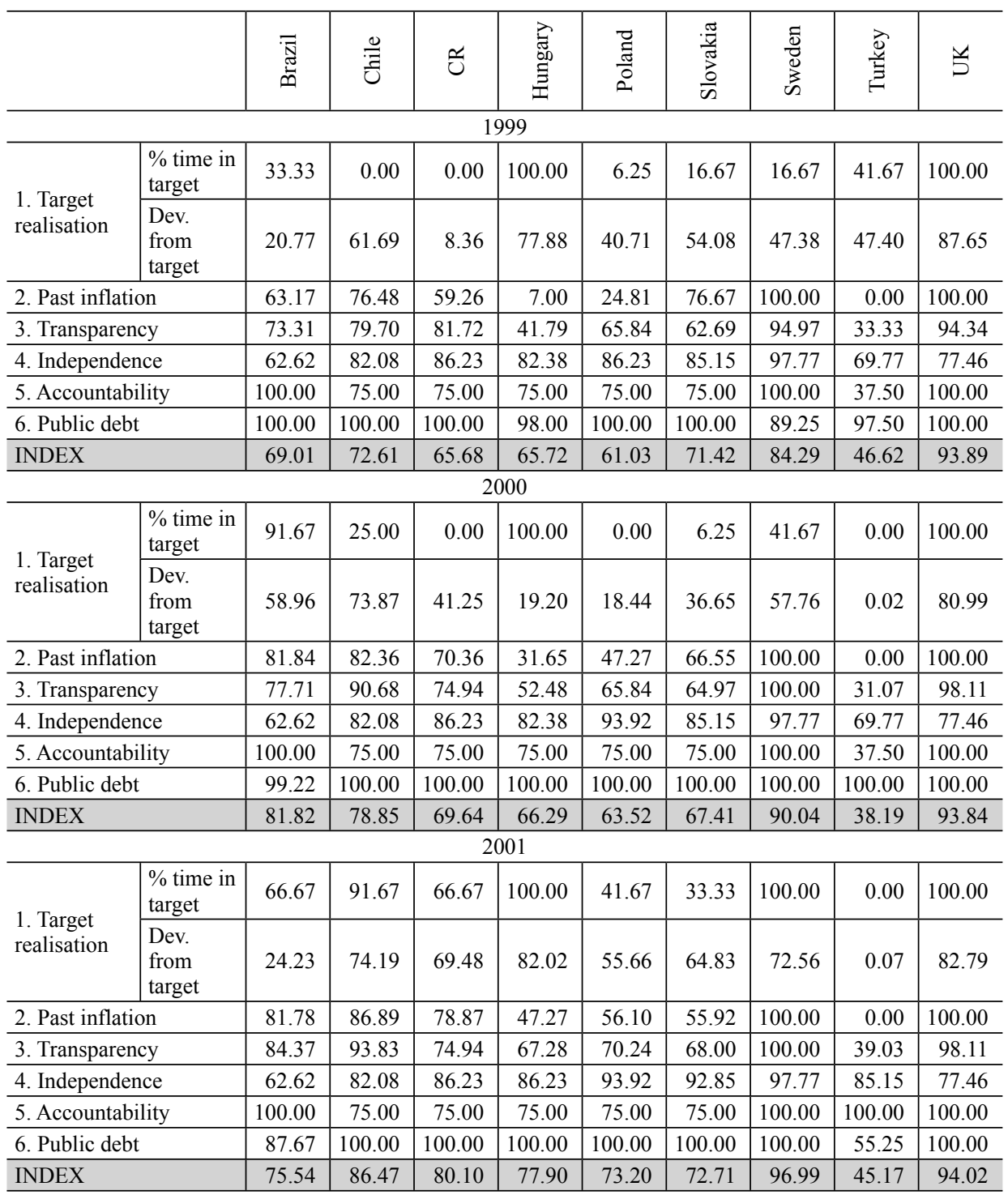


Table continued

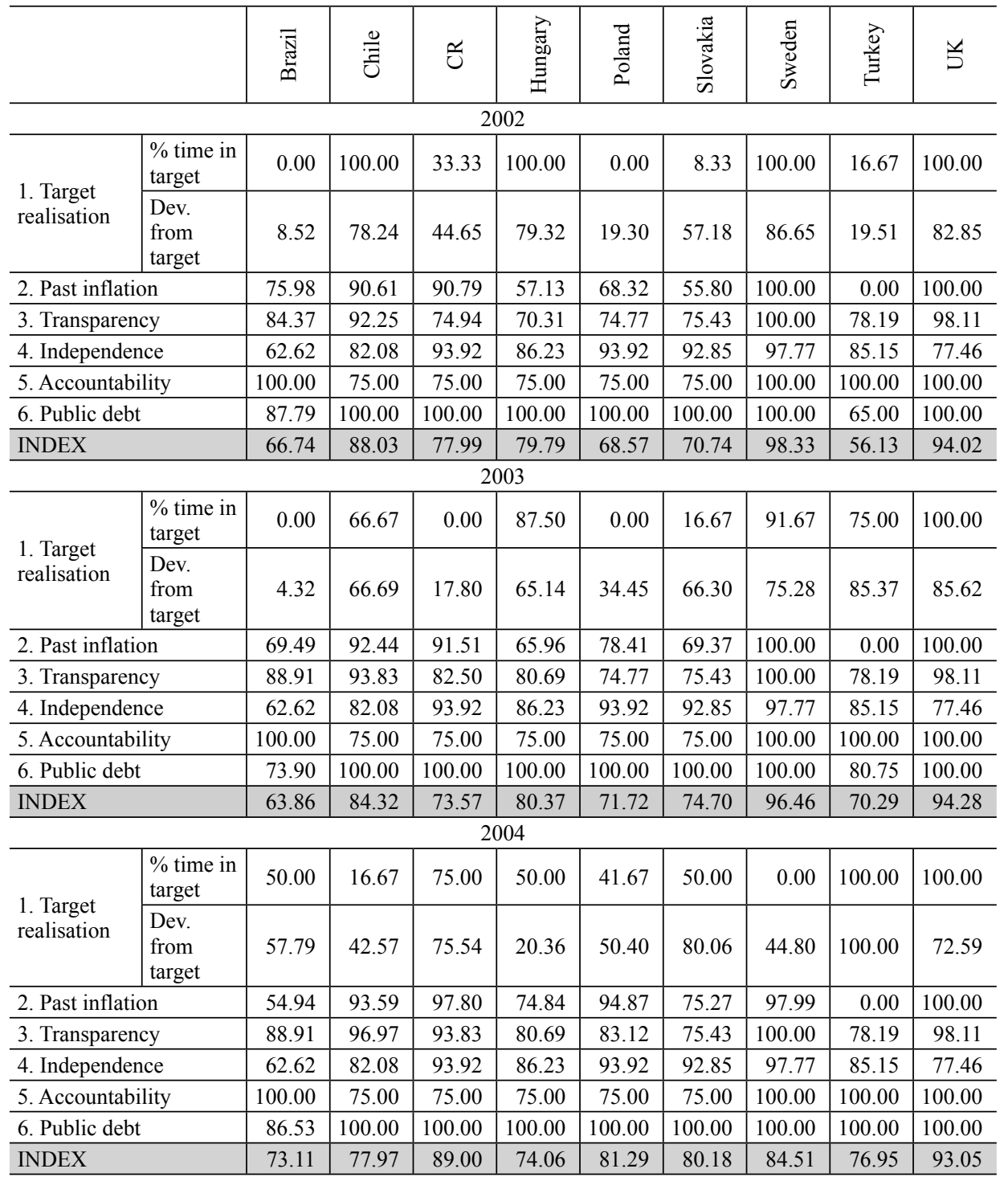


Table continued

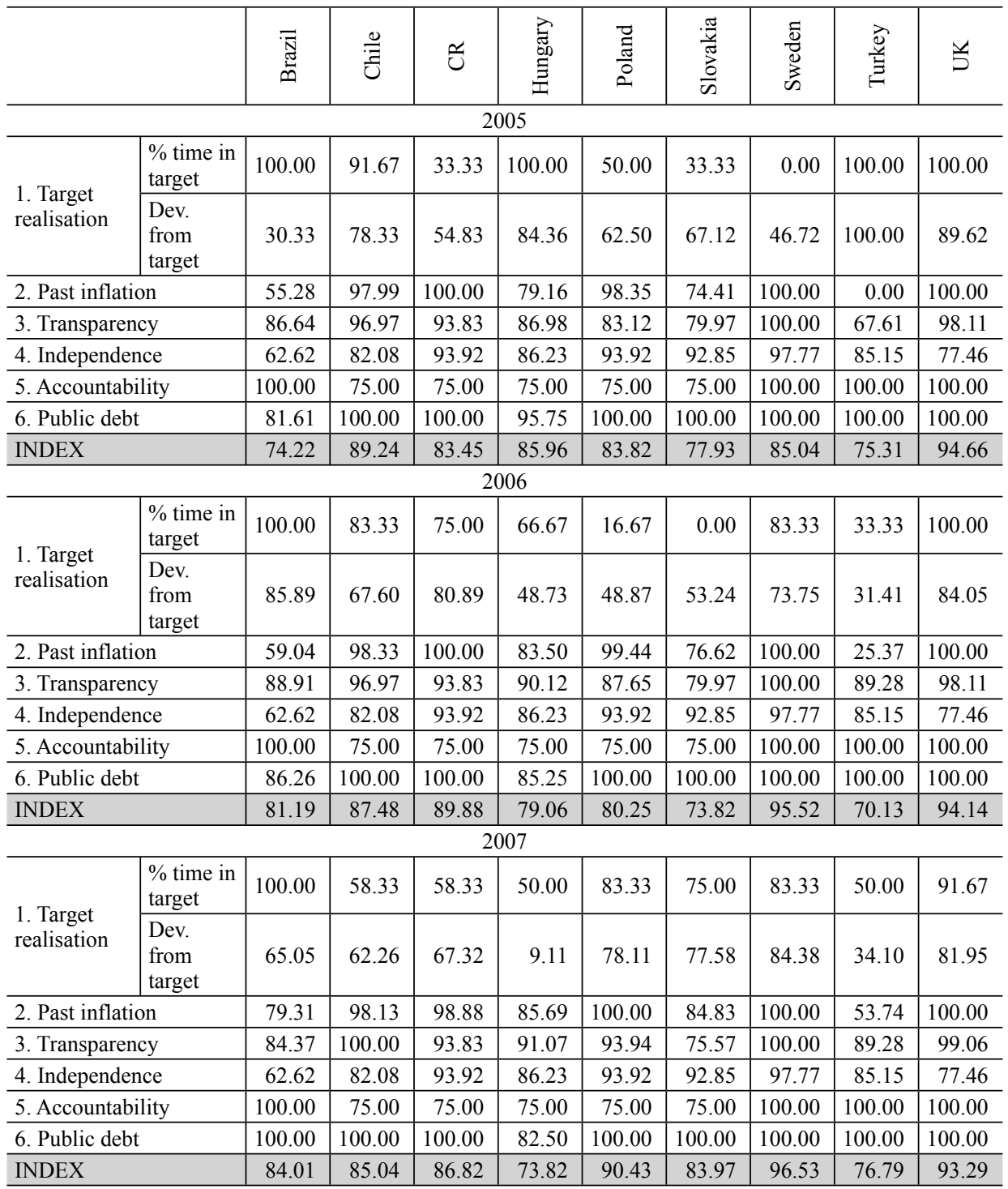

Source: Own calculations. 


\section{APPENDIX 2}

\section{Coefficient on the inflation target in equation (9) (at the end of each year)}

Financial analysts

\begin{tabular}{|l|c|c|c|c|c|c|c|}
\hline & Brazil & Chile & CR & Hungary & Poland & Slovakia & Turkey \\
\hline 2001 & - & - & - & - & 0.76 & - & - \\
\hline 2002 & -0.04 & - & 0.43 & - & 0.84 & - & - \\
\hline 2003 & -0.15 & - & 0.87 & - & 0.85 & 0.87 & - \\
\hline 2004 & 0.72 & 0.81 & 0.95 & 1.46 & 0.82 & 0.85 & 1.04 \\
\hline 2005 & 0.86 & 0.81 & 0.90 & 0.38 & 0.90 & 0.91 & 0.74 \\
\hline 2006 & 0.85 & 0.82 & 0.84 & 0.03 & 0.81 & 0.74 & 0.75 \\
\hline 2007 & 0.75 & 0.84 & 0.79 & 0.74 & 0.84 & 0.74 & 0.21 \\
\hline
\end{tabular}

\section{Consumers}

\begin{tabular}{c|c|c|c|c|c|c}
\hline & CR & Hungary & Poland & Slovakia & Sweden & UK \\
\hline 2001 & 0.10 & - & -0.20 & - & 0.62 & - \\
\hline 2002 & 0.07 & - & -0.26 & - & 0.78 & 0.98 \\
\hline 2003 & -0.08 & - & -0.07 & 0.14 & 0.91 & 0.45 \\
\hline 2004 & 0.00 & 0.28 & -0.01 & 0.05 & 0.87 & 0.25 \\
\hline 2005 & -0.07 & 0.03 & 0.05 & 0.06 & 0.79 & 0.50 \\
\hline 2006 & -0.02 & -0.26 & 0.06 & -0.10 & 0.78 & 0.03 \\
\hline 2007 & -0.13 & -0.05 & 0.07 & 0.23 & 0.65 & -0.07 \\
\hline
\end{tabular}

Source: Own calculations.

\section{Coefficient on the inflation target in equation (10) (at the end of each year)}

Financial analysts

\begin{tabular}{c|c|c|c|c|c|c|c}
\hline & Brazil & Chile & CR & Hungary & Poland & Slovakia & Turkey \\
\hline 2001 & - & - & - & - & 0.95 & - & - \\
\hline 2002 & - & - & 0.40 & - & 0.94 & - & - \\
\hline 2003 & 0.74 & - & 0.81 & - & 0.86 & 0.86 & - \\
\hline 2004 & 0.74 & 0.80 & 0.83 & 0.74 & 0.85 & 0.81 & 0.75 \\
\hline 2005 & 0.77 & 0.80 & 0.86 & 0.72 & 0.90 & 0.88 & 0.64 \\
\hline 2006 & 0.80 & 0.81 & 0.74 & 0.79 & 0.84 & 0.67 & 0.71 \\
\hline 2007 & 0.82 & 0.84 & 0.86 & 0.89 & 0.80 & 0.59 & 0.54 \\
\hline
\end{tabular}




\section{Consumers}

\begin{tabular}{c|c|c|c|c|c|c}
\hline & CR & Hungary & Poland & Slovakia & Sweden & UK \\
\hline 2001 & 0.03 & - & -0.25 & - & 0.62 & - \\
\hline 2002 & -0.11 & - & -0.24 & - & 0.74 & -0.77 \\
\hline 2003 & -0.03 & - & -0.10 & 0.36 & 0.67 & 0.80 \\
\hline 2004 & 0.00 & -0.23 & -0.03 & 0.16 & 0.84 & 0.43 \\
\hline 2005 & -0.02 & -0.32 & 0.08 & 0.10 & 0.80 & 0.86 \\
\hline 2006 & -0.16 & -0.37 & 0.09 & 0.10 & 0.80 & 0.03 \\
\hline 2007 & -0.22 & -0.41 & 0.05 & 0.36 & 0.73 & 0.87 \\
\hline
\end{tabular}

Source: Own calculations. 